\title{
Денисова И.А. \\ Частотно-пространственное распределение \\ биоэлектрической активности коры мозга при музыкальной творческой деятельности у музыкантов
}

В работе представлены результаты исследования функциональных, пространственных и структурных коррелятов музыкальной творческой деятельности с иелью выявления мозговых механизмов, лежащих в основе творчества. Выявлены различия в специфике спектральныххарактеристик мощности и характере когерентных связей у испытуемых в прочессе решения творческой задачи для разных частотных диапазонов.

Ключевые слова: невербальная креативность, ЭЭГ, спектральная мощность, когерентность, частотный диапазон.

С давних пор творчество интересовало ученых всех эпох и вызывало желание создать «теорию творчества». История насчитывает огромное количество попыток найти универсальную формулу, применение которой позволило бы творить бесценные произведения искусства, создавать по заказу шедевры. Уж сколько раз пытались «мерить алгеброй гармонию»! Однако трудно сказать, что ученые смогли поставить точку в объяснении природы данного феномена. Мы можем констатировать возрастающий интерес к проблеме творчества, ее социальным аспектам (Г. Фишер), анализу когнитивных и эмоциональных составляющих креативности (Т. Любарта и К. Муширу), диагностике интеллектуальных и творческих способностей (А. Фройнда и Х. Холлинга), к проблеме соотношения интеллекта и творчества (Дж. Мейкер), к исследованиям эволюционного гения в музыке (П.А. Куличкин), психофизиологическим аспектам связи креативности с тревожностью, психологической защитой, с включенными в работу зонами мозга (И. Карлссон). На сегодняшний день все чаще появляются научные данные, описывающие результаты исследований особенностей мозговой активности во время творческого процесса в отличие от нетворческого, при решении творческих задач в зависимости от пола испытуемых, избранной ими стратегии решения задачи, типа, характера и степени сложности задач, уровня мотивации к нахождению решения (Н.П. Бехтерева, С.В. Медведев, С.Г. Данько, И. Карлсон, О.М. Разумникова, Н. Уэйнбергер, N. Jausovec, К. Jausovec, Martindale, Molle, H. Petsche). При этом стоит отметить, что особое значение приобретает изучение мозговых механизмов истинного, внутренне мотивированного творческого процесса. Таким спонтанным творческим актом является сочинение музыки. Выявление функциональных, пространственных и структурных коррелятов музыкальной творческой деятельности позволяет понять мозговые механизмы, лежащие в основе творческого процесса, найти, каким образом управлять и влиять на творческое состояние. Исследования нейрофизиологии музыкального творчества носят пока фрагментарный характер (Р.А. Павлыгина, В.И. Давыдов, А.В. Сулимов, Ю.В. Любимова, Д.С. Сахаров, Т.Д. Панюшева, К.J. Pallsen, E. Brattico, 
C. Bailey, A. Korvenoja, J. Koivisto, A. Gjedee, N. Ann, L. Gabora, Th. Bever, R. Chiarello), в то время как научный интерес к этой сфере когнитивной науки продолжает расти. Актуальность исследования вызвана противоречием между постоянно растущим интересом к выявлению закономерностей функционирования мозга во время творческого процесса (в частности, во время невербальных форм творческой активности), с одной стороны, и недостаточным уровнем теоретической и прикладной базы психофизиологических и нейрофизиологических исследований лиц, занимающихся невербальным творчеством, прежде всего, во время самого творческого процесса - с другой. Особую сложность представляет организация эксперимента, максимально приближенного к естественному, и отсутствие однозначной интерпретации и классификации продукта эксперимента как истинно творческого.

Цель работы - исследовать особенности частотно-пространственного распределения биоэлектрической активности коры мозга при музыкальной творческой деятельности у музыкантов. Объектом исследования стали практикующие музыканты-профессионалы, имеющие профильное музыкальное образование.

Мы предположили, что при рассмотрении характеристик ЭЭГ у музыкантовкомпозиторов могут быть выявлены области мозговой активности, вовлеченные в процесс сочинения музыки, отличающиеся от тех, которые задействованы в реализации других видов музыкальной деятельности (восприятия, воспроизведения). В процессе исследования предполагалось решить следующие задачи: 1) изучение значения мощностей, а также когерентных связей в различных частотных диапазонах в фоне и используемых функциональных пробах: восприятие музыкального отрывка, воспроизведение услышанного музыкального отрывка, сочинение собственной мелодии, релевантной определенному эмоциональному состоянию, вызванному прослушанным отрывком; 2) проведение сравнительного анализа показателей мощностей в различных диапазонах при сравнении функциональных проб; 3) выявление специфических зон мозговой активации, присущих исключительно процессу сочинения музыки на основании сравнительного анализа показателей мощностей в различных диапазонах при функциональных проб; 4) изучение внутри- и межполушарных связей (при анализе результатов использовались только достоверные когерентные связи высокого порядка с показателем выше 0,7) при сочинении музыки и выявление специфики сочинения по этим показателям в отличие от фона; 5) проведение математической обработки данных с помощью методов математической статистики: Т-критерий Стьюдента и дисперсионного анализа MANOVA.

Для изучения функциональной организации мозга испытуемых во время выполнения музыкальной деятельности использовался метод ЭЭГ. Регистрация ЭЭГ осуществлялась при помощи электроэнцефалографа «Энцефалан», версия «Элитная-М» производства МТБ «Медиком» (Таганрог) по международному стандарту установки электродов по схеме 10-20\%. Для регистрации электрической 
активности мозга устанавливался 21 электрод, применялась монополярная схема с ипсилатеральными ушными референтами. Так же были установлены полиграфические каналы (ЭОГ, ЭМГ, ЭКГ, КГР) с целью подавления артефактов. Исследовались следующие частотные диапазоны: дельта1 (0,5-2,0 Гц) и дельта2 (2,0-4,0 Гц), тета1 $(4,0-6,0$ Гц), тета2 (6,0-8,0 Гц), альфа1 (8,0-10,5 Гц), альфа2 (10,5-13,0 Гц), бета1 $(13,0-24,0$ Гц) и бета2 (24,0-35,0 Гц). Для анализа выбирались безартефактные отрезки ЭЭГ длительностью по 10 секунд. Во время эксперимента показатели ЭЭГ регистрировались в спокойном состоянии (фоновая ЭЭГ с закрытыми глазами) и при выполнении функциональных проб (восприятие, воспроизведение и сочинение). В начале каждого опыта 1 минуту регистрировали ЭЭГ, когда испытуемый пребывал в состоянии спокойного бодрствования с закрытыми глазами при отсутствии звуковых и зрительных стимулов (проба 1). Эти данные рассматривались как фоновые. В следующей части опыта испытуемому через наушники подавали классическую музыку фиксированной мощности (60 Дб) и в течение 1 минуты регистрировали ЭЭГ (проба 2). В эксперименте в качестве классической музыки использовался фрагмент из оперетты Штрауса «Летучая мышь», характеризующаяся мажорной эмоциональной окраской. Перед этим испытуемому предлагалась следующая инструкция: «Прослушайте музыку и постарайтесь определить, какие эмоции она у вас вызывает». В следующей пробе (проба 3) испытуемый должен был воспроизвести про себя услышанный музыкальный отрывок. Затем перед испытуемым ставилась следующая задача: «Постарайтесь сочинить собственную мелодию, чтобы она носила такой эмоциональный окрас, как и ранее услышанный вами отрывок; а после исследования будет необходимо воспроизвести придуманную мелодию письменно или устно» (проба 4). Далее испытуемому предлагался другой музыкальный отрывок из балета «Пер Гюнт» Э. Грига», характеризующаяся минорной эмоциональной окраской, с ним было необходимо проделать ту же процедуру. Для оценки качественнных характеристик полученных мелодий их передавали на рассмотрение экспертов, преподавателей Ростовской консерватории имени Рахманинова. Далее анализировались ЭЭГ-данные тех испытуемых, у которых результаты третей пробы были оценены как высококреативные.

В результате сравнительного анализа спектральной мощности ЭЭГ между показателями каждой из функциональных проб (проба 2, проба 3, проба 4) с учетом использования мелодии с определенной эмоциональной окраской выявлены области коры специфичные именно для процесса сочинения музыки в отличие от других видов музыкальной деятельности. Анализируя результаты исследования мы исходили из современных представлений дельта-диапазоне. С точки зрения ряда исследователей: Л.И. Афтанас, Н.В. Ревы, А.А. Варламова, С.В. Павлова, В.П. Махиева дельта-колебания представляют из себя не только коррелят сниженного функционального состояния (сон, патология), но и коррелят сопутствующих компонентов активного состояния [6]. Так, в процессе генерации эмоций наблюдается усиление мощности в дельта-диапазоне. В нашем исследовании наибольшие изменения мощности в дельта-диапазоне п во фронтальных отделах и окципитальных зонах. 
Различные аспекты переработки музыкальной информации связаны с деятельностью многочисленных мозговых структур, одни из которых обеспечивают восприятие музыки (например, височные доли мозга функционально связаны с пониманием мелодии), а другие опосредуют развитие эмоциональных реакций (подкорковые структуры и лобные доли коры) [12].

В нашем исследовании повышение активности и значительной когерентности тета-ритма в теменно-затылочной области мы рассматриваем как отражение процесса активизации доступа и извлечения из памяти эмоциональной информации, процесс поиска новых, оригинальных решений.

Активность альфа-ритма ассоциируется с текущим функциональным состояние человека, на которое оказывает воздействие характер музыки (её мощность, стиль). При сочинении музыки с минорной эмоциональной окраской возрастала мощность во фронтальных и заднее-темпоральных зонах правого полушария в альфа-диапазоне.

В нашем исследовании повышение активности в бета1- и бета2-частотных диапазонах в префронтальной области правого полушария и окципитальной области левого полушария можно рассматривать как отражение активации творческого процесса при создании музыкального рисунка мелодии. Это подтверждается исследованиями, в которых выявлено, что правильную конструкцию языкового и музыкального синтаксиса (набора правил, определяющего надлежащее соединение элементов - нот и слов, соответственно) обеспечивает участок фронтальной коры, а другие участки отвечают за переработку связанных с ним компонентов языка и музыки. Н.П. Бехтерева также указывает, что при решении творческих дивергентных заданий в правой лобной доле (ПБ 10, 11, 44, 45, 46, 47), а также в теменно-затылочных областях слева $(П Б 67,7,19)$ прослеживалось локальное повышение кровотока [3]. В исследовании О.М. Разумниковой значительное увеличение бета2-ритма как коррелята успешного дивергентного мышления наблюдалось во фронтальных и теменных зонах. При этом наблюдается мозаичный характер организации нейронных ансамблей с диффузно-представленной синхронизацией в бета2-диапазоне, которая представляет собой коррелят «дифференцированного внимания», обеспечивающего широко распределённые по разным участкам коры процессы селекции информации, необходимые для решения проблем открытого типа - в нашем случае создания музыкального произведения [7].

В исследовании эмоционального воздействия на мозг музыкальных аккордов отмечается, что ответная реакция при восприятии минорных аккордов по сравнению с мажорными проявлялась в повышенной активности миндалины, ретроспинальной коры, ствола мозга и мозжечка. На важности ретроспинальной области в процессе обеспечения эмоций указывала и Н.П. Бехтерева [2].

В результаты анализа когерентных связей между фоновыми показателями и показателями функциональных проб «сочинение музыки» выявлено, что в процессе сочинения музыки наблюдается увеличение значений внутриполушарной 
когерентности в передних отделах правого полушария коры и в передних отделах левого полушария. Причем такая активация характерна для дельта-, тета- и альфа-частотных диапазонов. Подобная синхронизация тета-ритма во фронтальных регионах коры часто наблюдается в ситуациях с когнитивным усилием и нагрузкой на память [3]. В бета2-диапазоне выявлено повышение внутриполушарных длинно-дистантных связей между передними и задними отделами правого полушария. Что касается межполушарного взаимодействия, то оно наиболее ярко представлено в передних отделах мозга между гомологичными отведениями в дельта2-диапазоне. Таким образом, исследования показали, что внутриполушарные когерентные связи во время сочинения музыки практически равномерно распределены в обоих полушариях без значимого доминирования одной из гемисфер.

Усиление когерентных связей альфа-ритма в темпоральных и фронтальных областях у музыкантов может иметь значение активации ментальных процессов поиска. Происходит своеобразное сканиров ания («считывания») информации и имеет место тесная связь с механизмами восприятия и памяти.

В бета1- и бета2-частотных диапазонах динамика распределения когерентных связей следующая: выражена интеграция передних и задних областей в правом полушарии, что означает активное вовлечение в совместную работу париетальных, окципитальных и темпоральных областей.

Ослабление функциональных связей между полушариями у музыкантов может также указывать на более независимую работу полушарий, на раздельную обработку информации на этапе решения невербальной творческой задачи. В исследовании Н.П. Бехтеревой, Ж.В. Нагорновой так же, как и в нашем исследовании, выявлена независимая и параллельная работа полушарий в процессе невербального творчества. Авторы полагают, что уменьшение когерентных связей в высокочастотных диапазонах ЭЭГ между полушариями при выполнении творческих заданий указывает на уменьшение влияния левого (контролирующего) полушария в процессе невербального творчества [2]. Это предположение подтверждает и выявленное в нашем исследовании снижение когерентности биопотенциалов коры мозга в левом полушарии.

Стоит отметить, что число значимых когерентных связей в левом полушарии при сочинении мажорной мелодии значительно больше, чем в правом, что отражает паттерн ЭЭГ-активации, характерный для переживания положительных эмоций, которые присутствуют в процессе создания мелодий с мажорной эмоциональной окраской.

Таким образом, как специфику музыкального творческого процесса можно констатировать независимое, но параллельное активное функционирование полушарий при музыкальной творческой деятельности. При этом наибольшее значение приобретают фронтальная, темпоральная и окципитальная области коры, выполняя интегрирующие функции организации процессов внимания, эмоциональной регуляции и стратегий решения проблемы в целом. 


\section{Литература}

1. Базанова О.М, Афанас Л.И. Индивидуальные показатели альфа-активности электроэнцефалограммы и невербальная креативность // Рос. физиол. журнал им. И.М. Сеченова. - 2007. - № 93(1). - С. 14-26.

2. Бехтерева Н.П., Нагорнова Ж.В. Динамика когерентности ЭЭГ при выполнении заданий на невербальную (образную) креативность // Физиология человека. 2007. - T. 33. - № 5. - C. 5-13.

3. Воль $\phi$ Н.В., Тарасова И.В., Разумникова О.М. Половые различия в изменениях когерентности биопотенциалов коры мозга при образном творческом мышлении: связь с эффективностью деятельности // Журнал высшей нервной деятельности. - 2009. - Т. 59. - № 4. - С. 429-436.

4. Денисова И.А. Психофизиологический взгляд на творчество. Мозговые корреляты музыкального творчества // Вестник ЛГУ им. А.С. Пушкина. - СПб., 2010. Т. 5. Психология. - № 4. - С. 99-108.

5. Дикая Л.А. Нейрофизиологические корреляты музыкальной творческой деятельности // Сибирский психологический журнал. - Томск, 2010. - № 36. - С. 46-52.

6. Панюшева Т.Д. Музыкальный мозг: обзор отечественных и зарубежных исследований // Асимметрия. - 2008. - Т. 2. - № 3.

7. Разумникова О.М. Индивидуальные особенности полушарной активности, определяющие успешность решения эвристической задачи // Асимметрия. 2009. - T. 3. - № 1. - C. 37-50.

8. Разумникова О.М., Вольф Н.В., Тарасова И.В. Стратегия и результат: половые различия в электрографических коррелятах вербальной и образной креативности // Физиология человека. - 2009. - Т. 35. - № 3. - С. 31-41.

9. Старченко М.Г. Различия в мощности ЭЭГ у высоко и низкокреативых испытуемых // Четвёртая международная конференция по когнитивной науке: тезисы докл. Томск, 22-26 июня 2010 г. - Томск: Томский государственный университет, 2010. - T. 2. - C. 537-538.

10. Carlsson I., Wendt.P, Risberg J. (2000). On the neurobiology of creativity. Differencesin frontal activity between high and low creative subjects // Neuropsychologia 38:873-85.

11. Dietrich A. The cognitive neuroscience of creativity. Psychon. Bull. Rev. 11(6): 1011-1026. 2004.

12. Jausovec N, Jausovec K. (2000) EEG activity during the performance of complex mental problem. Int J Psychophysiology 36(1):73-88.

13. Jung-Beeman M., Bowden E.M., Haberman J., Frymiare J.L. et al. Neural activity when people solve verbal problems with insight. PLoS Biology. - 2004. - № 4. P. 0500-0510.

14. Martindale C., Hines D. Creativity and cortical activation during creative, intellectual and EEG feedback tasks // Biological Psychology. - 1975. - V. 3. -P. 71-80.

15. Petsche H. (1996) Approaches to verbal, visual and musical creativity by EEG coherence analysis. Int. J. Psychophysiology 24 (2):145-159. 